\title{
A REMATERIALIZAÇÃO HÁPTICA COMO RESPOSTA À DESMATERIALIZAÇÃO: UMA INTERPRETAÇÃO PELO ATUAL CONTEXTO TECNOLÓGICO
}

\section{A HAPTIC REMATERIALIZATION IN RESPONSE TO DEMATERIALIZATION: AN INTERPRETATION OF THE CURRENT TECHNOLOGICAL CONTEXT}

\section{Guilherme Philippe Garcia Ferreira, Dr. (UFPR) Adriano Heemann, Dr. (UFPR)}

\author{
Palavras Chave \\ Desmaterialização; Háptica; Interação \\ Key Words \\ Dematerialization; Haptics; Interaction
}

\section{RESUMO}

A computação aliada às redes de comunicação trouxe o referencial global para os ambientes domésticos. Neste meio, o acesso a conteúdos digitais parece se adequar aos conceitos da desmaterialização, um dos focos da sustentabilidade. Entretanto, há impacto perceptível nas relações que as pessoas tecem com o ambiente, com os recursos e também com outras pessoas. Percebe-se, dentre outros aspectos, um afastamento importante das relações táteis com os objetos. Ao mesmo tempo, observa-se em pesquisas a intenção de desenvolver informações háptica para dispositivos móveis. Com a intenção de compreender a relação entre os objetos digitais e a desmaterialização e o possível afastamento das relações táteis, exploramos o seguinte questionamento: seria a háptica uma resposta à emergente necessidade de desmaterialização? Embora não seja apresentada uma resposta definitiva, sugere-se que, se não uma relação direta, a háptica poderá auxiliar em alguns aspectos perceptivos da desmaterialização.

\section{ABSTRACT}

Computing allied to communication networks has brought the global benchmark for home environments. In this environment, access to digital content seems to fit the concepts of dematerialization, one of the focus of sustainability. However, there is noticeable impact on the relationships that people weave with the environment, with the resources and also with others. It is noticed, among other aspects, an important departure from tactile relations with objects. At the same time, it is observed in researches intended to develop haptic information to mobile devices. In order to understand the relationship between digital objects and dematerialization and the possible distance of tactile relationships, it is explored the question: would the haptic be a response to the emerging need for dematerialization? Although a definitive answer is not presented, it is suggested that, if not a direct relation, the haptics may help in some perceptive aspects of dematerialization. 


\section{INTRODUÇÃO}

O último século proporcionou uma das maiores evoluções tecnológicas da história da humanidade. A computação aliada às redes de comunicação trouxe o referencial global para os ambientes domésticos. Relações de consumo internacionais que antes eram dependentes de acordos comerciais entre grandes fornecedores passaram a fazer parte do cotidiano do consumidor. Informações, diversão e contato com pessoas do mundo todo permitem hoje um conhecimento e uma cultura multifacetada, ora apoiada na produção local, ora consumindo o produto global. Neste contexto, dispositivos móveis ocasionaram aplicativos que podem ser instalados em qualquer apareIho eletrônico que possua acesso à internet. $O$ conceito da desmaterialização se aplica a esses conteúdos digitais que, ao serem transmitidos e armazenados na nuvem computacional, reforçam a abordagem da sustentabilidade com redução de gastos energéticos e materiais.

Entretanto, ao digitalizar objetos e conteúdo que antes podiam ser manipulados e armazenados fisicamente percebe-se um afastamento da relação tátil, mais íntima e sensorial com os materiais. Em contraponto a este cenário, observam-se pesquisas em desenvolvimento que buscam aprimorar tecnologias de retorno tátil em dispositivos móveis para incrementar a interação do toque em tela, recuperando, assim, parte da informação física da matéria. Toma-se como base, então, o discurso de Silva (2017), que argumenta:

Ao mesmo tempo em que há hoje um movimento de desmaterialização (da informação, das mídias, das moedas, das relações sociais) em função da digitalização, ocorre, por outro lado, o aprimoramento de sensações imediatas e a intensificação da realidade por meio de tecnologias hápticas. (SILVA, 2017, p. 244)

Considerando o conteúdo apresentado por Silva (2017), o presente documento discute a desmaterialização por meio da intersecção de quatro componentes: a desmaterialização no contexto sustentável e do artefato digital; o usuário e suas interações; os dispositivos móveis e a háptica aplicada a objetos digitais. Este discurso é entremeado pela importância do tato na aquisição da informação, no envolvimento emocional e cognitivo e na representação da materialidade. Dessa maneira, com a intenção de compreender a relação dos objetos tangíveis e ao mesmo tempo alinhados às necessidades do design sustentável, parte-se do seguinte questionamento: seria a háptica uma resposta à emergente necessidade de desmaterialização?

\section{DESMATERIALIZAÇÃO}

A desmaterialização é uma das alternativas do design sustentável para buscar reduzir o impacto do humano no meio ambiente, mas o seu significado não é único e ganha contornos diversos na literatura. Portanto, faz-se necessário compreender como esta prática é apresentada nos discursos diversos que compõem o contexto desta pesquisa. Para Arcuri (2016, p. 14): "Desmaterialização pode ser definida como a mudança no montante de desperdício de bens industriais, tanto sob a perspectiva da produção quanto do consumo". Esta mudança pode ser compreendida como a redução em volume de materiais, na reutilização de recursos, ou ainda na evidênciação da essência da coisa, como aponta Ranoya (2004):

A desmaterialização é uma operação na qual uma coisa é destituída de seu meio, sendo considerada apenas a sua essência como sendo a coisa, e tomado seu invólucro descartável. O jornal, por exemplo, com a internet sofreu a desmaterialização; ver o jornal hoje significa ler suas notícias em qualquer meio que seja (no próprio jornal, na tela de um computador, no celular, ou impressas em uma folha a parte). (RANOYA, 2004, p. 30)

Para o autor, a desmaterialização possui representatividade na adequação dos meios originários às novas possibilidades de transmissão da informação facilitada pela tecnologia. Assim, um objeto que era essencialmente tangível, como o jornal, ganha contornos variados no cenário digital. Ribeiro (2007, p. 37) aponta "para uma sociedade cujo transporte e comunicação foram desmaterializados em informação à velocidade da luz, mesmo aquilo que é sólido passa a ser considerado dentro de uma nova lógica que é a da transmissão imediata". Em Bilik; Heemann (2016), discute-se esse contexto ao apresentar dados quanto ao consumo de papeis em atividades educacionais. $\mathrm{Na}$ avaliação dos autores, fica claro que a desmaterialização destes materiais, aproveitando as suas capacidades tecnológicas atuais, pode ter um impacto positivo sob a luz do Ecodesign. Corroborando a esta abordagem, Arcuri (2016, p. 14) afirma que "reuso, redução e reciclagem são ações que melhoram o impacto ambiental e contribuem para a desmaterialização, e, cada vez, existem mais consumidores engajados e mobilizados por esses discursos". Neste mesmo contexto, Arcuri $(2016$, p. 11) reforça que "a desmaterialização é vista como o processo de ver as posses desaparecendo fisicamente da vida dos consumidores por meio de doação, gift-giving, venda, descarte ou digitalização".

Trazendo estavisão paraas manifestações arquitetônicas, 
Ribeiro considera que durante a Era da Informação ocorre uma intencionalidade de fusão digital, na qual a arquitetura recebe contornos tecnológicos, como painéis e mostradores, desmaterializando sua significação originária tátil e visual, sendo então representadas pela imagem digital. Nesta mesma direção, o autor reflete que:

A sociedade da informação presenciou a desmaterialização de muito do que sempre fora visível e palpável. A comunicação instantânea seguiu-se ao rápido transporte de dados e à decodificação automática de informações, e a criação da realidade teve finalmente lugar em ambientes puramente digitais. Uma vez desmaterializada a presença, era natural supor a desmaterialização também da arquitetura, espaço onde as pessoas exercem suas presenças. (RIBEIRO, 2007, p. 33)

A consideração de Ribeiro, parece compreender a aproximação de experiências cada vez mais imerssivas nos ambientes virtuais. Hoje em dia, utilizando dispositivos vestíveis, como visualizadores de realidade aumentada, é possível acessar ambientes digitalizados e interagir com os mesmos. Em um contexto mais casual, é possível acessar através dos navegadores de internet museus que oferecem passeios virtuais, espaços compartilhados em jogos de simulação, como também conhecer locais por meio das imagens capturadas em mapas digitais. Esta junção de tecnologias não deve ser confundida, de acordo com Ranoya (2004), ao que acontece com periféricos cada vez mais integrados:

Da mesma maneira, não podemos confundir a re-significação de um aparato com sua desmaterialização. Quando temos um aparelho celular e uma máquina fotográfica (dois objetos e dois signos distintos), e fundimos os dois aparelhos em um só, não estamos desmaterializando nada nem criando interfaces novos; estamos apenas resignificando algo: criando novas palavras, novos usos, novos imaginários, novos conceitos, novos significados para este equipamento que permanece sendo tanto máquina fotográfica quanto celular. (RANOYA, 2004, p. 32)

De acordo com o autor, a desmaterialização é uma prática que não é percebida na vida cotidiana, pois assim como as novas interfaces são assimiladas, a desmaterialização se integra ao contexto do usuário com poucas interferências. No contexto da redução dos volumes de materiais e da energia necessária para desenvolver produtos, Arcuri (2016) afirma que, embora seja inerente ao contexto digitalizado, esta não é sua única forma de entendimento. Na opinião da autora, a desmaterialização: produtos têm ficado mais leves e menores com o avanço tecnológico: computadores, TVs, máquinas de lavar, carros. O processo de desmaterialização da sociedade tem sido percebido. Alguns autores têm usado o termo desmaterialização para descrever o estágio evolutivo lógico em que se encontram as economias avançadas, nas quais a necessidade por materiais foi substancialmente saciada e diminuída. Desmaterialização pode ser definida como a mudança no montante de desperdício de bens industriais, tanto sob a perspectiva da produção quanto do consumo. (ARCURI, 2016, p. 13)

Neste sentido, Ranoya (2004, p. 32) propõe que "a atuação da desmaterialização é no sentido oposto: ao invés de construir um conceito, ela tenta desmontá-lo". Esta desconstrução do conceito significante do objeto tenta identificar aquilo que realmente designa a funcionalidade da coisa e adéqua esta função a novos meios. Arcuri (2016), ao discutir o contexto da leitura de livros físicos ou digitais, apresenta um modelo (Figura 1) que considera rituais de materialização e rituais de desmaterialização.

Com este modelo a autora discursa sobre a representatividade da coisa, o livro físico x o livro digital, na manutenção dos significados. Para Arcuri (2016), isto se evidencia ao considerar que existem rituais de materialização, nos quais o usuário realiza ações de identificação, aquisição e organização do objeto. Esta posse tem valor frente à história da própria pessoa, ou seja, sobre todo o arcabouço de conhecimentos e experiências que esta pessoa possui e definindo um objeto singularizado. Este objeto tem, então, significado e representação únicos para o indivíduo. De acordo com a autora:

Os rituais de desmaterialização do objeto singularizado podem ser considerados como uma continuidade do processo de auto-conhecimento, iniciado com os rituais de materialização. A desmaterialização para o indivíduo que singulariza o objeto é complexa, pois envolve sentimento, apego, cuidado, ou seja, está embutida em sua história de vida. Para um colecionador de livros, o descarte simples pode ser difícil e às vezes, até impensado. Alternativas de desmaterialização mais aceitáveis seriam a doação ou a digitalização do conteúdo. (ARCURI, 2016, p. 43)

Ao considerar outros indivíduos diante do conhecimento que foi repassado ou descartado, este se torna parte do imaterial ou, no caso da digitalização, do virtual. Ora, se um 
livro digital pode ser identificado, adquirido e organizado, logo possui também valores e significados dos rituais materiais, embora em si o objeto seja apenas um conjunto de dados interpretado e exibido por uma interface.
Conforme for a atuação das tecnologias de desmaterialização, não se produzirá mais nenhum tipo de peça de comunicação fixa e estática como a comunicação impressa: o ePaper (comentado anteriormente) é como uma tela de computador,

Figura 1: Rituais de Materialização e Desmaterialização

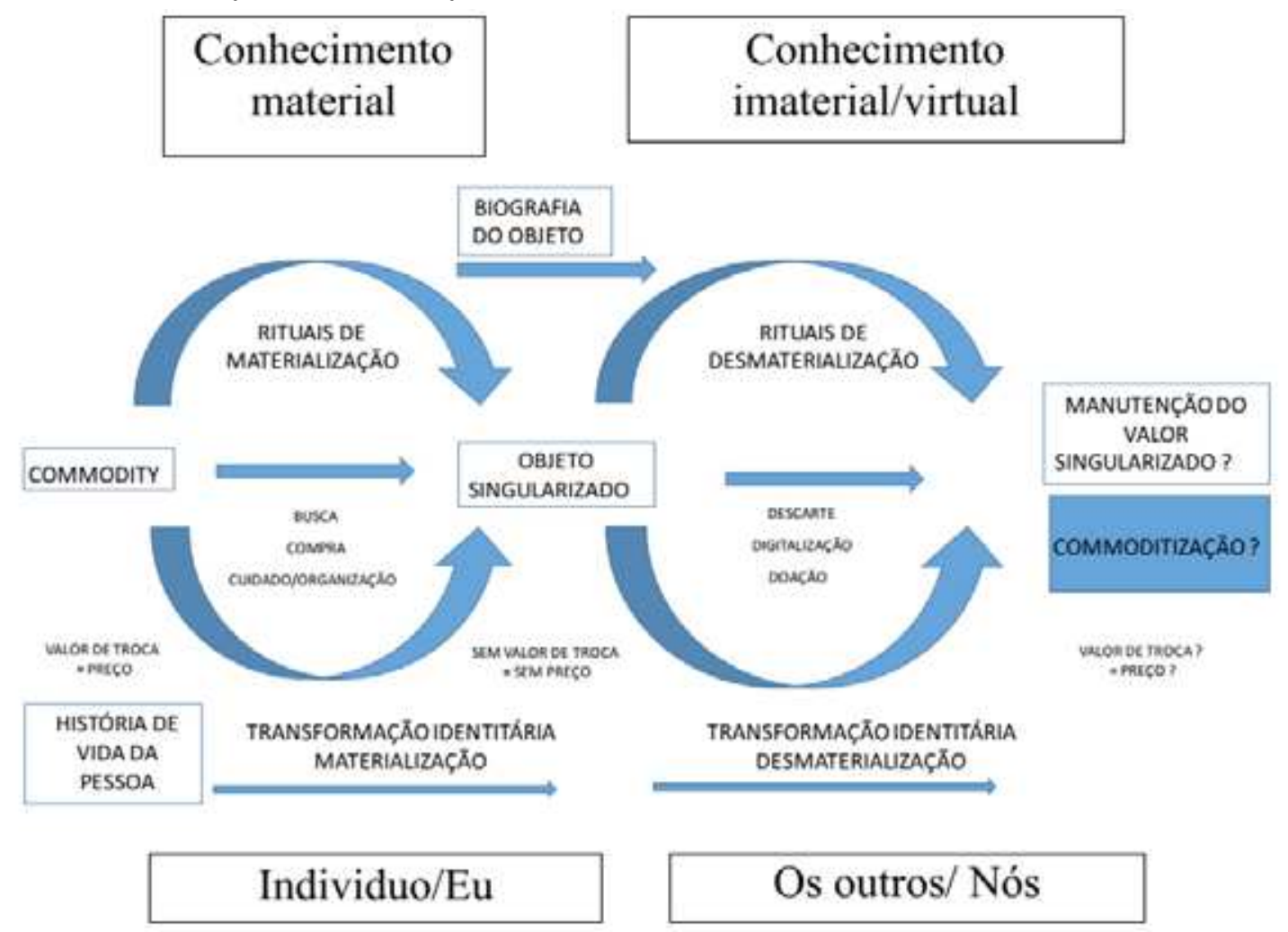

Fonte: (ARCURI, 2016, p. 43)

\section{A RELAÇÃO DE USO COM O MEIO DIGITAL}

A tecnologia impacta diretamente as relações que as pessoas tecem com o ambiente, com os recursos e também com outras pessoas. No contexto digital, surgem novas formas de consumir produtos, serviços e ainda leituras diferenciadas da interação com o meio e com os indivíduos. Considerando esta recente transformação das relações sociais e da própria sociedade, Arcuri (2016, p. 11) aponta um "contraponto ao desejo de posse e acumulação física dos consumidores. A realidade digital abre inúmeras possibilidades de consumo e tem modificado a relação dos indivíduos com os objetos físicos e as posses materializadas". No digital, o conceito da desmaterialização ganha força dentro do discurso sustentável, permitindo que dispositivos tecnológicos sejam portadores de grande parte da informação necessária ao dia a dia. Nesta direção, o trabalho de Ranoya (2004) traça uma perspectiva fortemente desmaterializada. Segundo o autor: e dispensará o papel; os outdoors serão substituídos por telas de vídeo, e o rádio e TV serão transformados em outra coisa com recepção/interpretação de sinais digitais. (RANOYA, 2004, p. 34)

Apesar desta perspectiva, ainda se tem uma sociedade de consumo. Trabalhos como o de Marino et al. (2015, p. 128) salientam "a necessidade de desmaterializar os produtos e a mudança do conceito de 'bem-estar' se faz cada dia mais notável conforme observamos os efeitos decorrentes da atividade produtiva sobre o meio ambiente". Nas relações de consumo, a tecnologia parece ser capaz de agrupar indivíduos mesmo que remotamente distantes. Como mostra Arcuri (2016, p. 11), "os consumidores se organizam em blogs e fóruns, discutem informações sobre os produtos e assumem papeis ativos em redes sociais, processos de crowdsourcing, crowdfunding e outros tipos de tecnologias". Observa-se, então, que mesmo a comunicação 
realizada por meio das redes sociais pode ser uma forma de perceber a desmaterialização. Ao discutir a relação das pessoas com a internet, Silva (2012) afirma:

Nesse sentido, essa híbrida relação contemporânea de internet e seres humanos aliada à possibilidade de mobilidade com conectividade permite que o acesso ao "espaço virtual" não se configure em uma saída do "espaço real" para um lugar em outro plano, desmaterializado, mas, do contrário, é no próprio espaço das relações materiais na cidade que, digitalmente, a produção do conhecimento, a troca de informações, o acesso a redes sociais, dentre outras atividades, que podem ser realizadas. (SILVA, 2012, p. 9)

Conforme o autor, este espaço, apesar de digital, apresenta pontos positivos quanto à flexibilidade de atividades que podem ser realizadas com mobilidade. Nesta mesma direção, o discurso de Riberio (2015, p. 63) relata que "durante muito tempo, a convicção dominante em pesquisas era essa de que, ao adentrar no espaço virtual, o sujeito passava a habitar um universo imaterial, no qual incorporava um corpo desmaterializado". Entretanto, como observado anteriormente no discurso de Silva (2012), é possível entender o meio digital como parte integrante do real. $\mathrm{O}$ que pode ser compreendido também através de Arcuri (2016, p. 2) é que "a desmaterialização dos itens pode ser uma forma de afastamento físico, mantendo o valor imaterial, garantindo o acesso, resguardando a singularidade do objeto e protegendo-o da commoditização". Ou seja, a garantia de singularidade do objeto aparentemente é uma característica que incorpora o real materializado.

O posicionamento de Ranoya (2004) oferece um contraponto a este entendimento ao considerar que existe um afastamento de práticas sociais nas relações mediadas pela tecnologias. Ao considerar tudo como dados, pode-se perceber um afastamento nas inter-relações pessoais, que é facilitado por tecnologias como os dispositivos móveis:

O telefone (ou o telefonar para alguém) fará parte apenas do mundo simbólico como representação de um comportamento, e não como representação de uma ação sobre um dispositivo material. A desmaterialização que transformou esse ato em dados transmitidos, equalizou a conversa telefônica (dados), textos (dados), imagens (dados), músicas (dados), planilhas e cálculos (dados) [...] ao estacionar nosso automóvel na porta de um edifício, para dar carona para um amigo, podemos chamá-lo em casa sem saímos do veículo ligando para ele de nosso aparelho celular, ou podemos enviar para ele uma mensagem de texto SMS que ele receberá no seu celular. (RANOYA, 2004, p. 23)

Nesta mesma direção, Moura (2011) também percebe que a desmaterialização dos dispostivos móveis e dos computadores retiram o sujeito do mundo real e o levam para um contexto de dados onde o próprio sujeito é integrado ao objeto em um contexto digital:

Não se trata, agora, da transparência de um mundo que o ecrã torna integralmente visível e acessível, mas da transparência da ligação a esse mundo, do frame, conseguida através da desmaterialização progressiva do processo de mediação e, com ela, do fim da radical oposição entre sujeito e objecto, que agora confluem no território da imagem, da informação e do código. (MOURA, 2011, p. 172)

Visão similar é apresentada por Riberio (2015, p. 64), pois considera que ao ser incluso na desmaterialização o usuário deixa suas relações perceptivas para ser elemento participante do meio. O autor ainda destaca que "o corpo do espectador, antes fisicamente afastado da obra, funde-se ao 'corpo' da obra por meio da experiência da fruição, assim, desmaterializando-se". Os modos de acessar estes meios digitais são diversos. Por exemplo, para realizar a leitura de um conteúdo é possível utilizar tábletes, computadores, leitores e-ink ou até mesmo desconsiderar a informação escrita e recorrer ao conteúdo em áudio. Neste contexto a relação física de posse e desejo entra em conflito pois o digital pode ser simplesmente armazenado como qualquer outro dado (ARCURI, 2016). Esta alteração na distribuição da informação afeta as práticas de consumo. Como aponta Ranoya (2004, p. 34) "desmaterializar os Meios de Comunicação significa extirpar todo o processo produtivo e todas as atividades correlatas que ocorrem em seu entorno, e reduzi-los a aquilo que eles se pretendem a fazer: persuadir". Mas, há reações de materialização que se afastam desse sentido da desmaterialização, como discorre Sobral et al. (2015):

A democratização da tecnologia digital traz em sua esteira a reestruturação de aspectos da vida cotidiana. Se a tecnologia da informação e da comunicação contribui para a virtualização e desmaterialização de rotinas cotidianas antes apoiadas em artefatos físicos, a impressão 3D (também chamada de prototipagem rápida) abre outras possibilidades agora relacionadas a materialização de objetos. (SOBRAL et al., 2015, p. 2)

Percebe-se um discurso quanto à imaterialidade 
destas relações e uma busca por recuperar a tangibilidade física dos objetos. De acordo com Sobral et al. (2015), vivem-se ciclos de consumo para os quais o digital se torna parte essencial do dia, mas as relações físicas entre pessoas e objetos se perdem. Na próxima sessão este discurso tem continuidade e observam-se os dispositivos móveis como objeto de acesso à desmaterialização e como recurso por si desmaterializado.

\section{DISPOSITIVOS MÓVEIS}

Os dispositivos móveis, como celulares e tábletes, têm se tornado presentes em grande parte das interações tecnológicas do cotidiano. Se por um lado eles auxiliam a promoção da informação facilitando o acesso a documentos diversos de modo virtual em qualquer lugar do globo, existe também uma necessidade de aprimoramento da imersão dessa tecnologia. Ao explorar o contexto dos livros, Arcuri (2016) tece um paralelo evolutivo da relação de comunicação humana. O que antes era imaterial e realizado através da linguagem falada se transformou em materialidade com adventos como a prensa de Gutenberg. Mais tarde, a tecnologia retoma esta materialidade e a transfere para o contexto digital, desmaterializando o livro físico para que se torne livro digital. Confirmando este discurso Bilik e Heemann (2016), ao tratar de leitores e-reader, consideram a

[...] a existência de um exemplo de desmaterialização do papel denominado Kindle, desenvolvido pela empresa Amazon. No Kindle, podem ser utilizadas alternativas para o conforto do leitor, como a escolha da tela e-Ink, que emula o aspecto do papel impresso. Outro exemplo de ferramenta que pode dispensar o uso de papel são os tábletes. Eles oferecem mobilidade, são menores e mais leves do que um computador comum, dispõem de espaço para amplo armazenamento de informação, como apostilas, livros, revistas, filmes, etc. em uma só mídia. (BILIK e HEEMANN, 2016, p. 48)

Conforme Arcuri (2016, p. 25), "essa transformação da relação com a informação, com o conhecimento e com a materialidade do livro físico, tem impacto na percepção identitária dos consumidores". Moura (2011) explora este contexto ao discorrer que:

Esta lógica mediadora que tem no ecrã uma fronteira, um quadro que permite que uma realidade alternativa se apresente no espaço do observador sem que com ele se confunda, está a ser ameaçada à medida que a evolução tecnológica desmaterializa as ligações e, com elas, os limites estáveis que possibilitavam a coexistência entre um lado de cá (real) e um lado de lá (virtual), durante séculos perfeitamente definidos enquanto opostos. (MOURA, 2011, p. 169)

Assim, como aponta Moura, parece que a relação física com o objeto digital é característica desta reconfiguração entre o real e o virtual, permeando os diferentes contextos com fluidez crescente. A relação tátil com os dispositivos móveis surge então como uma possibilidade de aproximar movimentos comuns do mundo real ao contexto digital. Neste sentido Riberio (2015) afirma:

O que a oralidade - antes do advento da escrita - evidenciava, era a utilização de inúmeros sentidos - ou seja, o advento de uma multissensorialidade, retomada e ressignificada pelo advento dos dispositivos móveis. Adotados pelo homem como "extensões de si mesmo". Com o ingresso das tecnologias touchscreen passamos a deixar de lado os mouses, botões e canetas stylus e outros dispositivos de condução passiva e deixamos tal condução a cargo de nossos dedos (RIBERIO, 2015, p. 114).

O pesquisador ainda explora a percepção e a interação física recorrendo aos trabalhos da série Mobile Feelings de 2001, que utilizavam do retorno tátil para simular as batidas do coração de usuários distantes um do outro na exposição Ars Eletrônica, de 2001. Para o autor, as obras "levantavam questões sobre a comunicação em rede e suas subjetividades anônimas, da sensorialidade x sensibilidade poética, comunicação tátil à distância" (RIBERIO, 2015, p. 124). Apesar dos notórios avanços desta época na tecnologia dos dispositivos móveis, principalmente na interação verbal (entre usuários), visual e auditiva, o uso do tato nas interações ainda era incipiente. Somente em 2007 é que a tecnologia do toque em tela, segundo Riberio, foi popularizada em parte pelo lançamento do táblete da Apple, iPad 1. Ao contar com uma interface que promovia a interação tátil com uma boa usabilidade, o produto tornou comum o conceito de interação gestual nos dispositivos móveis.

O desenvolvimento das telas sensíveis ao toque permitiu uma aproximação do usuário ao conteúdo digital. Ação e reação com a ponta dos dedos reduziram o distanciamento cognitivo percebido em interações mediadas por dispositivos de rastreamento como mouses e joysticks. Atualmente, percebe-se um empenho crescente para não apenas interagir de forma tátil com estes dispositivos, mas também apreender estas interações. $O$ interesse e a 
pesquisa pelas propriedades hápticas aplicadas a dispositivos móveis têm se tornado cada vez mais emergentes, em contrapartida, os produtos disponíveis hoje no mercado ainda utilizam prioritariamente o retorno vibracional de forma pouco expressiva e, por vezes, incômoda ao consumidor, segundo Seifi; MacLean (2017). Na sequência o contexto háptico é explorado para compreender seu papel frente à desmaterialização.

\section{HÁPTICA}

A desmaterialização demanda, muitas vezes, um afastamento daquilo que é material e físico também nas relações cotidianas. Por exemplo, um livro digital não possui as mesmas propriedades sensoriais táteis que um livro físico, não ocupa espaço em uma estante, não representa uma busca cansativa para um colecionador. O usuário do livro digital "não mais será capaz de sentir o cheiro do livro, de limpar a poeira, de passar as páginas, de exibi-lo esteticamente na estante ou tê-lo fisicamente ao alcance das mãos e dos olhos", como destaca Arcuri (2016, p. 44). Por outro lado, observa-se no mercado uma intenção crescente de prover os aparatos digitais com relações físicas, seja através de jogos, nos quais os usuários dependem do rastreamento do corpo para agir sobre os avatares, dispositivos com interação gestual, ou mesmo dispositivos móveis que acrescentam o referencial tátil para promover a imersão. A intencionalidade da interação tátil em dispositivos computacionais não é nova, segundo Riberio (2015):

A história das telas táteis - também conhecidas como ecrãs táteis ou touchscreens - começou em 1965, na Inglaterra, quando o pesquisador E.A. Johnson publicou um trabalho em torno da tela capacitativa ao toque. A primeira tela tátil foi desenvolvida para fins militares, mais especificamente, utilizada em radares de controle de tráfego aéreo. Não era um equipamento multitouch - portanto, suportava apenas um toque por vez, e identificava apenas duas posições: toque e ausência de toque. (RIBERIO, 2015, p. 104)

Assim como outras tecnologias, a transferência de aplicações especializadas para ambientes comuns não foi imediata. Somente em 1983 um computador pessoal usou o referencial de toque "o HP 150 -, que possuía um sistema infravermelho que reconhecia o toque dos dedos. Operado pelo sistema MSDOS e com um monitor CRT da Sony, de 9 polegadas" (RIBERIO, 2015, p. 105). O sentido háptico, entretanto, surge com maior interesse nos dispositivos móveis apenas na década de 2000, sendo que a intencionalidade inicial era de atuar como dispositivo de alerta ou indicação de estado do aparelho e só recentemente se tornou foco de pesquisas, conforme Ferreira (2014), com a ideia de ser uma fonte de informação e interação complexa. Para Silva (2017, p. 238), "enquanto o tato diz respeito à sensação física proporcionada pelo órgão da pele, o 'háptico' é entendido como a relação do tato com outros sentidos, com os órgãos internos do corpo e também com as sensações cerebrais provocadas pelo contato." O retorno háptico, em suas diferentes modalidades, permite criar experiências de interação como a identificação de objetos digitais, somente através do tato, conforme visualizado na (Figura 2).

Figura 2: Identificação de formas pelo tato.

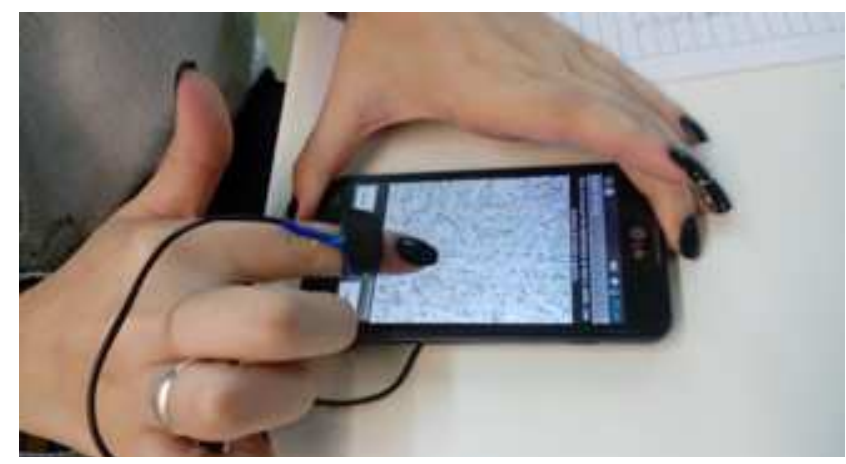

Fonte: elaborado pelos autores (2017)

Neste experimento simples, mas que demonstra empiricamente uma conjectura teórica importante com relação a formação da imagem tátil do usuário em interação com um dispositivo digital esclareceu-se que embora seja um processo mais cansativo é possível identificar formas e padrões vibracionais. No experimento, ao rastrear a tela do dispositivo com o dedo, o usuário percebe uma forma geométrica através da vibração que não pode ser adquirida pelo olhar. Este tipo de relação se torna ainda mais importante considerando um usuário com deficiência visual. Durante a execução dos testes os usuários julgaram importante a percepção tátil ser desenvolvida para "manipular" os objetos digitais.

Sobral et al. (2015, p.7) relata que as interações de gestos, toque e sentido tátil "possibilitam a ampliação do 'olhar', a 'leitura' e a interpretação de informações para todos nós. Mas, para pessoas de baixa visão, ou cegas, estes recursos se tornam imprescindíveis e o tato é o principal sentido de percepção". Para Silva (2012, p. 8), "é a partir do sistema háptico que o corpo explora o ambiente e age sobre ele, o modificando-o. Portanto, é prioritariamente este sistema, associado a operações mentais, o 
responsável pela construção, no ciberespaço, das rotas e nexos pelos quais o internauta navega".

Aparentemente, o tato é capaz tornar matéria aquilo que para outros canais sensoriais seria mera informação, como discorre Riberio (2015):

O que a touchscreen - tela tátil - de dispositivos móveis torna possível vai muito além da praticidade de que o usuário "se liberte" de botões ou outro dispositivo para "tocar" a tela, acionando os controles de seus softwares. O que ela possibilita é que se acionem sensorialidades que as telas anteriores não acionavam, não por meio da utilização direta das mãos como acionando o corpo inteiro, em todos os seus sentidos. (RIBERIO, 2015, p. 117)

As possibilidades hápticas dos dispositivos atuais e, principalmente, dos dispositivos que ainda estão em desenvolvimento com capacidades de resolução tátil refinadas, poderão tornar o tato digital mais próximo do real. Tomemos como exemplo o caso da Fujitsu. Em 2014, durante a Conferência Mundial Móvel sediada em Barcelona, na Espanha, a empresa apresentou um protótipo de táblete que simula as texturas que aparecem em sua tela. Essa tecnologia recebe o nome de "tecnologia sensorial tátil" e emprega vibrações ultrassônicas ou eletricidade estática para proporcionar sensações hápticas ao toque da tela, fazendo o usuário perceber pelo tato aquilo que também percebe pela visão (Figura 3):

Figura 3: Protótipo háptico exibindo um Crocodilo.

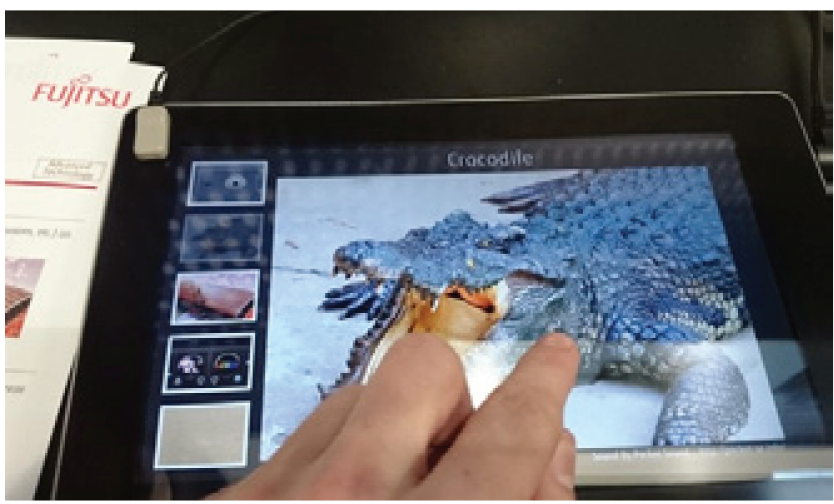

Fonte: (FUJITSU, 2014)

Apesar de ainda não existirem produtos com esta tecnologia distribuídos massivamente, a háptica parece se aproximar cada vez mais do cotidiano do usuário dos dispositivos móveis. Neste contexto, como aponta Parisi et al. (2017), é possivel sentir texturas, formas e contornos de objetos digitais. Segundo Silva (2017, p.
247), "o sentido háptico carregaria em si um potencial estético-político de transformação por estimular o corpo, retirando-o do lugar de espectador passivo, de desengajamento e de distanciamento para um estado ativo, de contato e de proximidade".

Aqui considera-se razoável a noção de que a realidade aumentada através da háptica poderia auxiliar usuários em ambientes controlados a ter uma experiência mais profunda com objetos sensíveis como, por exemplo, obras de arte e livros. Geralmente, ao efetuar leituras em conteúdo de texto digital, como e-books, perde-se parte da experiência física, mas por meio da háptica esta informação pode ser explorada e ainda aumentada pela própria história. Como exemplo dessa observação, recorre-se ao táblete com luvas hápticas (Figura 4), apresentado por Israr et al. (2015).

Neste sistema de leitura para crianças, o táblete conta com duas luvas hápticas na parte posterior nas quais o usuário insere as mãos; na tela, histórias são exibidas e aumentadas através de padrões hápticos diretamente nas mãos do usuário. A esse respeito, Bilik e Heemann (2016 p. 47) observam que "em termos conceituais, a desmaterialização em projetos parece ocorrer quando um produto passa a ter sua função e seu valor de uso significativamente ampliados em comparação a produtos similares".

Figura 4: Táblete com luvas hápticas.

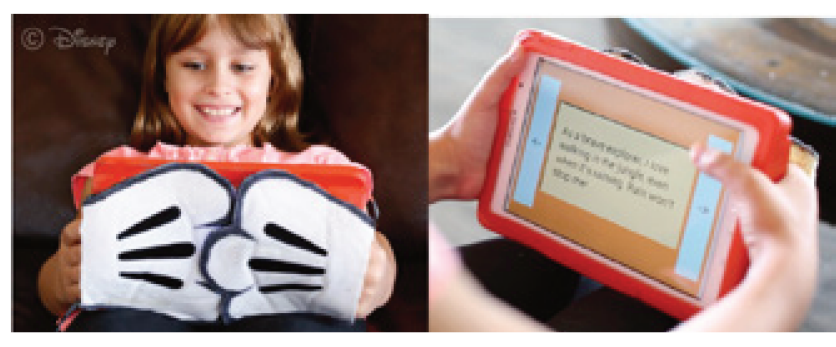

Fonte: (ISRAR et al., 2015, p. 12)

No ponto de vista de Israr et al. (2015), o estímulo tátil durante a leitura das amostras gerou interesse em virtude da capacidade de sentir os objetos do conteúdo digital e imersão pela percepção do usuário vivenciando a informação digital. Esta integração também é explorada por Riberio (2015) ao considerar a interação com artefatos artísticos:

A criação da a touch screens possibilitou o desenvolvimento de uma vasta e diferenciada criação nas manifestações artísticas conhecidas como táteis, entretanto, a noção de arte tátil não se limita às funcionalidades dos softwares ativados por meio delas. Tocamos obras de arte em 
ambientes imersivos, pressionando nossos dedos em telas táteis, pisando em sensores, apertando controles ou clicando em mouses, ou por meio de dispositivos de vídeo, som, infravermeIhos, de calor ou luz por meio das quais possamos interagir com os softwares envolvidos nas obras. (RIBERIO, 2015, p. 126)

Parece coerente a noção de que o aparato háptico nos dispositivos trouxe uma experiência que rematerializa o conteúdo desmaterializado do livro. A háptica se mostra capaz de evidenciar relações até mesmo afetivas com os objetos digitais. Bumatay (2015) produz um sistema háptico simples para a respiração controlada. Em outra esfera do conhecimento Munawar e Fischer (2016) demonstram uma aplicação complexa da háptica para cirurgias médicas. Já, a háptica no livro digital, traz à tona e reforça laços sensoriais de grande importância. Possibilita uma vivência na imersão com o livro multissensorial baseada na "experiência física, o gesto tátil, a experiência com o espaço, com os limites da imaginação e do real, dos sonhos e dos desejos", conforme Arcuri (2016, p. 83). Assim, o discurso de Silva (2017, p. 244) se potencializa ao sugerir que se recorre ao tátil "como um sintoma da sociedade contemporânea em resposta à desmaterialização por que passam as mediações e as relações humanas".

\section{CONSIDERAÇÕES FINAIS}

A desmasterialização faz parte dos procedimentos necessários para tornar a relação produtiva mais sustentável. Entretanto, nos dispositivos móveis parece que o alcance da desmaterialização extrapola o contexto do equipamento. Nestes casos, a desmaterialização também se refere aos dados que este carrega, às interpretações e interações que possibilita e até mesmo às relações do usuário com o meio. Como apontam os estudos aqui mencionados, enquanto no passado se valorizavam as experiências táteis e as relações do dia a dia com artefatos, hoje se destaca o visual, pois se atravessa um período da experiência ótica impulsionada, aparentemente, pela desmaterialização.

Os dispositivos móveis, como parte deste processo de desmaterialização e também ressignificação, ganham discursos múltiplos, ora de intimidade com o usuário, que possui muitos dados armazenados no equipamento, ora de desconexão com o ambiente e com o próprio usuário, que substitui o equipamento por um novo modelo. Percebe-se um momento de liquidez e volatilidade em que relações com objetos e indivíduos são mantidas através do digital. Portanto, sugere-se que o retorno háptico é uma maneira de rematerializar o objeto digital e de ressignificar, deste modo, a interação do usuário com artefatos.

Entretanto, ainda é pouco compreendida a relação tátil dos usuários com dispositivos eletrônicos principalmente ao considerar os recentes desenvolvimentos da tecnologia háptica. Essa tecnologia ainda se mostra reservada a aplicações específicas ou a seu aspecto meramente vibracional. Portanto, argumenta-se que a háptica tem um potencial latente importante não apenas no campo da desmaterialização mas, sobretudo, como promovedora de novas percepções até então desconhecidas no mundo material.

Com este discurso, não se pretende afirmar que a háptica é uma resposta consistente à desmaterialização. Talvez ela faça parte de um esforço de reconectar sujeitos aos objetos, sejam estes tangíveis no universo físico ou tangibilizados através do processamento digital. Uma noção mais clara a este respeito parece ainda demandar uma descrição dos impactos das tecnologias vindouras na relação com os usuários e entre usuários. Esta pode ser uma lacuna a ser investigada.

\section{REFERÊNCIAS}

ARCURI, A. G. O ritual de desmaterialização dos objetos singularizados e a transformação da relação pessoa-objeto, 2016. Fundação Getulio Vargas. Disponível em: <http://hdl.handle.net/10438/16225>. Acessado em 27/11/2017.

BILIK, T. C.; HEEMANN, A. A DESMATERIALIZAÇÃO COMO ESTRATÉGIA DE ECODESIGN: OBSERVAÇÃO DE UM CENTRO EDUCACIONAL. MIX Sustentável, v. 2, n. 2, p. 44-50, 2016.

BUMATAY, A. L. Investigating the Role of Biofeedback and Haptic Stimulation in Mobile Paced Breathing Tools, 2015. Texas A\&M University.

FERREIRA, G. P. G. Percepção háptica no design colaborativo síncrono mediado pelo computador, 2014. Universidade Federal do Paraná. Disponível em: <http://dspace.c3sl.ufpr.br/dspace/handle/1884/35385>. Acessado em: 22/2/2017.

FUJITSU. Haptic interface of the future. Disponível em: <http://journal.jp.fujitsu.com/en/2014/04/15/01/>. Acessado em: 22/2/2017. 
ISRAR, A.; LEHMAN, J. F.; KLATZKY, R. L. FeelSleeve : Haptic Feedback to Enhance Early Reading. Proceedings of the 33rd Annual ACM Conference on Human Factors in Computing Systems., p. 10151024, 2015. Disponível em: <http://dl.acm.org/citation. cfm?id=2702396 $>$. Acessado em: 22/2/2017.

MARINO, G. A. G.; RINCÓN, J. A. S.; PINHEIRO, O. J.; DA CRUZ LANDIM, P. "MINUTEROS": APROXIMAÇÃO DE PESSOAS TECNOLOGIA OBSOLETA AO SERVIÇO DA COMUNICAÇÃO. MIX Sustentável, v. 1, n. 2, 2015.

MOURA, C. Frame (d): a lógica da visão, 2011. Edições Universitárias Lusófonas. Disponível em < http://hdl.handle.net/10437/6066>. Acessado em: 22/2/2017.

MUNAWAR, A.; FISCHER, G. Towards a haptic feedback framework for multi-DOF robotic laparoscopic surgery platforms. 2016 IEEE/RSJ International Conference on Intelligent Robots and Systems (IROS), 2016.

PARISI, D.; PATERSON, M.; ARCHER, J. E. Haptic media studies. New Media \& Society, v. 19, n. 10, p. 1513-1522, 2017. SAGE Publications. Disponível em: <https://doi.
article/pii/S1071581917300617> Acesso em 27/11/2017.

SILVA, A. C. A. POLÍTICAS CULTURAIS E CIBERCULTURA: O QUE MUDA NA SOCIEDADE CONTEMPOR NEA? Anais do VIII Seminário Internacional de Políticas Culturais, p. 12, 2012.

SILVA, T. T. O sentido háptico e a politização da imagem contemporânea. Discursos Fotográficos, v. 13, n. 22, p. 236-257, 2017.

SOBRAL, J. E. C.; CAVALCANTI, A.; EVERLING, M. T. Ver com as mãos: a tecnologia 3D como recurso educativo para pessoas cegas. 15th Ergodesign, Recife, 2015.

\section{AGRADECIMENTOS}

Os autores agradecem à CAPES e ao CNPq pelo apoio na forma de bolsa de estudos e bolsa de produtividade em pesquisa.
RANOYA, G. Tecnologias da desmaterialização. Novos Olhares, , n. 13, p. 22-35, 2004.

RIBEIRO, F. M. O virtual de baixa resolução: entre a visibilidade e a ilusão. Risco: Revista de Pesquisa em Arquitetura e Urbanismo (Online), n. 5, p. 33-52, 2007.

RIBERIO, G. S. Pela tela, pela janela: as funcionalidades da tela interativa em aplicativos de arte para dispositivos móveis (ipads), 2015. Espírito Santo: Universidade Federal do Espírito Santo. Disponível em: <http://dspace2.ufes.br/handle/10/2132> Acessado em 27/11/2017.

RODRIGUES, T.; SILVA, S. C.; LENCASTRE, P. DE. Need for touch-O impacto da informação háptica textual na interação de compra on-line, 2013.

SEIFI, H.; MACLEAN, K. E. Exploiting haptic facets: Users' sensemaking schemas as a path to design and personalization of experience. International Journal of Human-Computer Studies, v. 107, p. 38-61, 2017. Disponível em: <http://www.sciencedirect.com/science/ 